\title{
Metáfora conceptual y construcción del antagonista en el discurso parlamentario español
}

\author{
GRACIA PIÑERO PIÑERO \\ Universidad de Las Palmas de Gran Canaria
}

\section{Introducción}

El análisis que nos proponemos abordar en estas páginas parte de un marco teórico interdisciplinar, en el que intervienen enfoques diversos, que, sin embargo, comparten la consideración del discurso como práctica social, como escenario de la interacción y, consecuentemente, como resultado de una triple dimensión cognitiva, social e ideológica. Nos referimos particularmente al análisis crítico del discurso, a la teoría de la metáfora conceptual y, por último, a la noción de metadiscurso.

En efecto, el análisis crítico del discurso, que analiza el texto aunando su dimensión lingüística y su dimensión política y social, entiende la comunicación como un reflejo de los ámbitos y de las prácticas de la sociedad que la produce y pretende comprender los procesos a través de los cuales se generan los textos que estructuran las actividades de los agentes sociales. ${ }^{1}$

Estrechamente vinculados a los planteamientos defendidos por los estudios críticos del discurso se hallan los procesos de metaforización, examinados, en el seno de la lingüística cognitiva, a través de la teoría de la

1 Sobre la perspectiva del análisis crítico del discurso, véanse, entre otras, las referencias siguientes: Teun Adrianus van Dijk, Discourse Studies: A Multidisciplinary Introduction, 2 vols (London: Sage, 1997), II, Discourse As Social Interaction; Metaphor Analysis: Research Practice in Applied Linguistics, Social Sciences and the Humanities, ed. Lynn Cameron \& Robert Maslen (London: Equinox, 2010); Luis Enrique Concepción Montiel, 'El análisis del discurso y su relevancia en la teoría y en la práctica de la política', Revista Internacional de Pensamiento Político, 5 (2010), 15-32; y Ruth Wodak, 'Mediation between Discourse and Society: Assessing Cognitive Approaches in CDA', Discourse Studies, 8:1 (2006), 179-90. 
metáfora conceptual. ${ }^{2}$ Desde esta perspectiva, la metáfora se concibe como una herramienta de conceptualización del significado, y no como una fórmula retórica, que permite categorizar tópicos complejos y abstractos a través de su proyección sobre vehículos más sencillos, más concretos y, por ello, más asequibles.

La noción de metadiscurso, finalmente, en cualquiera de sus interpretaciones, desplaza el foco del contenido proposicional del texto para colocarlo en su componente social, comunicativo e interaccional. ${ }^{3}$ Surge así la idea de que el significado del texto es el resultado de un proceso de interacción entre productor y receptor, mediatizado por el propósito, el género y el contexto en el que tiene lugar la comunicación.

Sobre este andamiaje, examinaremos, a partir de un corpus de textos pertenecientes a la comunicación política, que se inscriben particularmente en el género del discurso parlamentario, las metáforas conceptuales y lingüísticas empleadas por los portavoces de los nuevos partidos políticos que se estrenaron en el Parlamento de España en la XI legislatura y que confirmaron su presencia en la siguiente (nos referimos a Ciudadanos y a Unidos Podemos y sus confluencias), para construir el retrato ideológico deslegitimador del antagonista político. ${ }^{4}$

En tales textos, la metáfora conceptual constituye una maniobra encaminada a la simplificación del universo complejo de saberes, creencias y opiniones de quien las emplea y de quien las recibe y, por tanto, colabora eficazmente en los procesos cognitivos que intervienen en la producción e

2 En relación con la teoría de la metáfora conceptual, puede verse George Lakoff \& Mark Johnson, Metaphors We Live By (Chicago/London: Univ. of Chicago Press, 1980); George Lakoff \& Mark Johnson, Philosophy in the Flesh: The Embodied Mind and Its Challenge to Western Thought (New York: Basic Books, 1999); Mark Johnson, The Body in the Mind: The Bodily Basis of Meaning, Imagination, and Reason (Chicago: Univ. of Chicago Press, 1987); George Lakoff, Women, Fire and Dangerous Things: What Categories Reveal about the Mind (Chicago/London: Univ. of Chicago Press, 1987); George Lakoff, The Political Mind. Why You Can't Understand 21 $1^{\text {st }}$-Century Politics with an $18^{\text {th }}$-Century Brain (New York: Penguin Books, 2008); George Lakoff \& Mark Turner, More Than Cool Reason: A Field Guide to Poetic Metaphor (Chicago/London: Univ. of Chicago Press, 1989); Eve Sweetser, From Etimology to Pragmatics: Metaphorical and Cultural Aspects of Semantic Structure (Cambridge: Cambridge U. P., 1990); Mark Turner, Reading Minds: The Study of English in the Age of Cognitive Science (Princeton: Princeton U. P., 1991); Peter Stockwell, 'Towards a Critical Cognitive Linguistics?', en Poetics, Linguistics and History: Discourses of War and Conflict, ed. Annette Combrink \& Ina Biermann (Potchefstroom: Potchefstroom U. P., 2001), 510-28; Zoltán Kövecses, Metaphor: A Practical Introduction (Oxford: Oxford U. P., 2002); y Zoltán Kövecses, Metaphor in Culture: Universality and Variation (Cambridge: Cambridge U. P., 2005).

3 Nos centramos, muy especialmente, en la propuesta que nos ofrece Ken Hyland, Metadiscourse: Exploring Interaction in Writing (London/New York: Continuum, 2005).

4 Naturalmente, en el corpus analizado es posible identificar otras muchas metáforas conceptuales, que, sin embargo, quedan excluidas de nuestro trabajo porque no responden a nuestro objeto de estudio. 
interpretación del discurso político, en la medida en que reduce la abstracción de la política a modelos más simples y fáciles de manejar; ${ }^{5}$ incorpora una relación entre la parte y el todo que la convierte en un procedimiento eficaz para aludir a cuestiones más amplias y complejas; ${ }^{6} \mathrm{y}$, por último, comunica gran cantidad de información de modo conciso, según demuestra Andrew Ortony con su tesis sobre la compacticidad de esta herramienta cognitiva. ${ }^{7}$

De igual modo, en el discurso parlamentario la metáfora se coloca al servicio de la persuasión, pues el productor textual, que a través de un proceso argumentativo persigue que el interlocutor comparta una creencia, recurre a ella por su capacidad para combinar la ruta central de la persuasión, de naturaleza lógica y racional, con la ruta periférica, de carácter emocional e irracional $;{ }^{8}$ con ella no solo activa estrategias argumentativas sino también, y muy especialmente, estrategias encaminadas a entrar en contacto con los afectos de la audiencia.

\section{Corpus y metodología}

El corpus de textos objeto de análisis, extraído de la página web oficial del Congreso de los Diputados de España (<http://www.congreso.es $>$ ), está constituido por el primero de los dos debates sobre la investidura del candidato a la presidencia del gobierno que tuvieron lugar en la XII legislatura española, celebrado durante los días 30 y 31 de agosto y 2 de septiembre de 2016, lo que incluye tanto el discurso del candidato a

5 A esta propiedad de la metáfora aluden los estudios de Walter Lippmann, Public Opinion (New York: Macmillan, 1922); Mark Jordan Landau, Brian P. Meier \& Lucas Allen Keefer, 'A Metaphor-Enriched Social Cognition', Psychological Bulletin, 136:6 (2010), 104567; y, por último, L. Elizabeth Crawford, 'The Role of Conceptual Metaphor in Memory', en The Power of Metaphor: Explaining Its Influence on Social Life, ed. Mark Jordan Landau, Michael. D. Robinson \& Brian P. Meier (Washington, DC: American Psychological Association, 2014), 65-83.

6 Sobre este aspecto de la metáfora conceptual, véase Murray Edelman, Politics As Symbolic Action: Mass Arousal and Quiescence (Chicago: Markham, 1971).

7 Andrew Ortony, 'Why Metaphors Are Necessary and Not Just Nice', Educational Theory, 25:1 (1975), 45-53.

8 A propósito de esta capacidad de la metáfora para combinar la ruta central y la ruta periférica de la persuasión, pueden consultarse las referencias siguientes: Michael Burgoon \& Gerald R. Miller, 'Prior Attitude and Language Intensity As Predictions of Message Style and Attitude Change Following Counterattitudinal Advocacy', Journal of Personality and Social Psychology, 20:2 (1971), 246-53; Michael Burgoon \& Erwin Bettinghaus, 'Persuasive Message Strategies', en Persuasion: New Directions in Theory and Research, ed. Michael E. Roloff \& Gerald Raymond Miller (Beverley Hill: Sage, 1980), 141-69; Kathleen Kelley Reardon, Persuasion: Theory and Context, foreword by Gerald R. Miller (Beverly Hills: Sage, 1981); Richard Petty \& John Cacioppo, Communication and Persuasion: Central and Peripheral Routes to Attitude Change (New York: Springer-Verlag, 1986); y Shelly Chaiken \& Charles Stangor, 'Attitudes and Attitude Changes', Annual Review of Psychology, 38 (1987), 575-630. 
presidente de gobierno, como las réplicas y contrarréplicas de los diversos grupos parlamentarios. Recordemos que esta legislatura confirma la presencia en la cámara de aquellas formaciones políticas que debutaron en el parlamento español en la legislatura anterior y que pusieron fin al bipartidismo instaurado en el país durante años. Tales formaciones se distribuyen, a lo largo de la citada XII legislatura, en dos grupos parlamentarios: de un lado, el de Ciudadanos, con su portavoz Albert Rivera; y, de otro, el Grupo Confederal integrado por Unidos Podemos, En Comú Podem y En Marea, representados respectivamente por Pablo Iglesias y Alberto Garzón, Xavier Domènech y Alexandra Fernández.

Se trata, por tanto, de un corpus perteneciente al discurso parlamentario, sobre el que en los últimos años han proliferado los estudios centrados particularmente en el proceso cooperativo de construcción de identidades que tiene lugar en este entorno institucional. En tales estudios, la definición de este tipo de discurso se ha afrontado tanto desde una perspectiva pragmalingüística, que lo registra como un género de la comunicación política, que incita a hacer; como desde una perspectiva retórica, que, aun reconociendo la presencia de elementos del género judicial y del género epidíctico, lo inserta en el género deliberativo. ${ }^{9}$

Por otra parte, el debate parlamentario, que es precisamente el subgénero al que se adscribe el corpus señalado, no presenta diferencias sustanciales en relación con otros tipos de debate, ${ }^{10}$ salvo las derivadas del contexto institucional específico en el que tiene lugar y que ocasiona, en opinión de Luisa Martín Rojo, ${ }^{11}$ dos rasgos singulares: en primer lugar, la concepción del parlamento como un espacio de enfrentamiento en el que confluyen diferentes representaciones de los acontecimientos; en segundo lugar, su alto grado de performatividad, en tanto que este tipo de debate no solo constituye una confrontación dialéctica, sino que, además, a través de él se realizan acciones políticas.

Con el propósito de identificar en el corpus señalado las metáforas objeto de análisis, hemos recurrido a la estrategia de búsqueda manual descrita por Anatol Stefanowitsch para la extracción de expresiones lingüísticas que

9 Véase, en este sentido, el trabajo de Cornelia Ilie, 'Parliamentary Discourse', en Encyclopedia of Language and Linguistics, ed. Keith Brown, 14 vols (Amsterdam/London: Elsevier, 2006), IX, 188-97.

10 A la naturaleza específica del debate parlamentario y a su contexto institucional se refiere Teun Adrianus van Dijk, 'Parliamentary Debates', en Racism at the Top: Parliamentary Discourse on Ethnic Issues in Six European States, ed. Ruth Wodak \& Teun Adrianus van Dijk (Klagenfurt: Drava Verlag, 2000), 45-78.

11 Luisa Martín Rojo, 'Enfrentamiento y consenso en los debates parlamentarios sobre la política de inmigración en España', Oralia, 3 (2000), 113-48. A propósito de otras notas específicas de la interacción que tiene lugar en el debate parlamentario, puede verse también Luisa Martín Rojo, 'Spain, Outer Wall of the European Fortress: Analysis of Parliamentary Debates on Immigration Policy in Spain', en Racism at the Top, ed. Wodak \& van Dijk, 169-221. 
manifiestan proyecciones conceptuales, pues, tal y como afirma el autor, 'conceptual mappings are not linked to particular linguistic forms'. ${ }^{12}$

Para ello, hemos procedido, en primer lugar, a la lectura de los textos con el fin de identificar los vocablos sobre los que los portavoces de las nuevas fuerzas parlamentarias proyectan metafóricamente la imagen del adversario político y su ideología.

Seguidamente, hemos confirmado el uso figurado de estos vocablos acudiendo a los repertorios lexicográficos, que, en opinión de Zoltán Kövecses, ${ }^{13}$ constituyen la principal fuente de información para decidir, desde una perspectiva sincrónica, si un determinado elemento léxico provoca en su contexto respectivo el tipo de disonancia cognitiva que señala la presencia de una metáfora, pues el dominio cognitivo sobre el que el hablante proyecta las nociones abstractas que pretende categorizar se materializa precisamente en estos lexemas. Por consiguiente, la corroboración de que tales vocablos responden a un uso metafórico, y no literal o metonímico, se ha efectuado a través del método del grupo Pragglejaz, ${ }^{14}$ que con una perspectiva científica avala esta presunción haciendo uso del diccionario y comparando el significado contextual del vocablo con su significado más básico, antiguo o relacionado con una acción corpórea.

Una vez configurado el inventario definitivo de metáforas lingüísticas, hemos inferido las metáforas conceptuales que subyacen en ellas, con el propósito de estudiar las correspondencias ontológicas y epistémicas existentes entre los dos dominios, fuente y meta, conectados a través de la metáfora. Su análisis cualitativo nos ha suministrado, finalmente, los cimientos sobre los que las nuevas formaciones políticas construyen el retrato ideológico del adversario así como las claves que nos han conducido a la interpretación de sus respectivos componentes emocional, ideológico y valorativo.

Con estos planteamientos, constataremos que los procesos metafóricos se comportan en este contexto como movimientos discursivos que, combinados con otros, contribuyen de modo esencial a la gestión del conocimiento en el discurso público y particularmente en el debate parlamentario, pues 'se

12 Anatol Stefanowitsch, 'Corpus-Based Approaches to Metaphor and Metonymy', en Corpus-Based Approaches to Metaphor and Metonymy, ed. Anatol Stefanowitsch \& Stefan Th. Gries (Berlin/NewYork: Mouton de Gruyter, 2006), 1-16 (p. 2).

13 Zoltán Kövecses, Metaphors of Anger, Pride, and Love: A Lexical Approach to the Structure of Concepts (Amsterdam/Philadelphia: John Benjamins, 1986); Zoltán Kövecses, Emotion Concepts (New York: Springer-Verlag, 1990).

14 Gerard J. Steen, Aletta G. Dorst, J. Berenike Herrmann, Anna Kaal, Tina Krennmayr \& Trijntje Pasma, A Method for Linguistic Metaphor Identification (Amsterdam/Philadelphia: John Benjamins, 2010). 
utilizan para introducir conocimiento nuevo a partir de su relación con conocimiento previo'. ${ }^{15}$

Tales metáforas, además, están diseñadas para persuadir al auditorio de que el grupo antagonista actúa al margen de los principios socialmente aceptados y, por consiguiente, responden a la estrategia de deslegitimación esencial al discurso político, que supone la autopresentación positiva del endogrupo, frente a su contrapartida, la presentación negativa del exogrupo. $^{16}$ En relación con el papel que desempeñan estas y otras estrategias de discurso en el debate parlamentario, señala Martín Rojo:

Debates and discussions break the reciprocal rule of protection of face, and are one of the most face-threatening contexts for the interlocutors. This is because the dynamics of the debate demand competition between the contenders; that is, they must criticise, disavow and delegitimize the adversary, his/her actions, views, and arguments, for the benefit of their own face. ${ }^{17}$

\section{Análisis}

La ya señalada concepción del parlamento como espacio de confrontación, de disensión, en el que los intervinientes han de pronunciarse pro et contra en torno a cualquier asunto objeto de discusión, convierte el discurso parlamentario en una arena en la que los interlocutores sociales construyen sus propias imágenes y, al mismo tiempo, construyen también las de sus respectivos adversarios. ${ }^{18}$

Este proceso de construcción de identidades de los interlocutores sociales, con concepciones heterogéneas sobre el mundo y sobre la organización de la sociedad, se materializa a través de estrategias discursivas muy diversas, de las que nos interesa, como ya hemos advertido, la metáfora conceptual, que, según vamos a constatar, se muestra como una herramienta de gran eficacia para el diseño y ejecución de la imagen negativa del antagonista político.

15 Teun Adrianus van Dijk, 'Discurso, conocimiento, poder y política: hacia un análisis crítico epistémico del discurso', en Más de ciencia del texto, ed. Ramón Almela Pérez, Revista de Investigación Lingüística, 13 (2010), 167-215 (p. 182).

16 En relación con la estrategia de deslegitimación propia del discurso político, destacan las aportaciones de Paul Chilton, Analysing Political Discourse: Theory and Practice (London/ New York: Routledge, 2004); y Elena Semino, Metaphor in Discourse (Cambridge: Cambridge U. P., 2008).

17 Martín Rojo, 'Spain, Outer Wall of the European Fortress', 180.

18 Véase, en este sentido, Kari Palonen, 'Speaking pro et contra: The Rhetorical Intelligibility of Parliamentary Politics and Political Intelligibility of Parliamentary Rhetoric', en The Parliamentary Style of Politics, ed. Suvi Soininen \& Tapani Turkka (Helsinki: The Finnish Political Science Association, 2007), 82-105. 
Las proyecciones metafóricas a las que acuden los portavoces parlamentarios de las nuevas agrupaciones políticas para trazar el retrato del adversario permiten identificar tanto metáforas correlacionales como metáforas intertextuales. ${ }^{19}$ Las primeras, las metáforas correlacionales, disponen de una base experiencial de naturaleza corpórea y, por tanto, proyectan el tópico del discurso sobre esquemas de imagen, que resultan de la interacción física de nuestros cuerpos con el entorno. ${ }^{20}$ Las segundas, las metáforas intertextuales, se perfilan sobre dominios fuente que surgen de la experiencia cultural del emisor a través de su contacto con textos relevantes, procedentes de la literatura, del cine, del arte, de la historia, de los medios de comunicación e incluso de conocimientos adquiridos en la escuela.

En el debate público, como veremos, unas y otras metáforas se emplean de manera consciente, en el contexto de una planificada política de imagen, para dibujar la ideología del antagonista político, una variable que incide de manera significativa sobre el modo en que el productor del texto construye su representación de la realidad y sobre el modo en que el receptor la deconstruye para interpretarla, según aseveran Robert Hodge y Gunther Kress. ${ }^{21}$ Todas ellas contribuyen a la construcción de un contexto comunicativo en el que 'disagreements and dialectical confrontations are allowed and tolerated without threatening the social relation, that is, without risking the parliamentary game'. ${ }^{22}$

Las metáforas aquí estudiadas atienden al retrato deslegitimador de dos adversarios recíprocos, que intervienen a través de sus respectivos portavoces: por un lado, el Grupo Parlamentario Confederado integrado por Unidos Podemos, En Comú Podem y En Marea; y, por otro, el grupo parlamentario de Ciudadanos. Ambos grupos, de ideologías contrapuestas, compiten a la hora de disputarse el voto de ese espacio de desencanto que ha ido surgiendo entre la ciudadanía española como consecuencia del desgaste experimentado en los últimos años por el bipartidismo del Partido Popular (PP) y del Partido Socialista Obrero Español (PSOE) y en el que pretenden instalarse estas nuevas formaciones políticas que se estrenaron en el Parlamento español, como ya hemos dicho, en la XI legislatura.

19 Sobre la distinción entre metáforas correlacionales y metáforas intertextuales, véanse Jörg Zinken, 'Ideological Imagination: Intertextual and Correlational Metaphors in Political Discourse', Discourse \& Society, 14:4 (2003), 507-23; y Jörg Zinken, Lina Hellsten \& Brigitte Nerlich, 'What Is "Cultural" about Conceptual Metaphors?', International Journal of Communication, 13:4 (2003), 5-29.

20 Sobre el concepto de esquema de imagen, puede consultarse Lakoff \& Johnson, Metaphors We Live By; y Johnson, The Body in the Mind.

21 Robert Hodge \& Gunther Kress, Language As Ideology (London/New York: Routledge, 1993), 15.

22 Martín Rojo, 'Spain, Outer Wall of the European Fortress', 180. 
Analizaremos, en primer lugar, el retrato negativo de Unidos Podemos y sus confluencias tal y como lo dibuja, mediante metáforas conceptuales, Ciudadanos a través de su líder Albert Rivera, quien en el transcurso de sus intervenciones subraya insistentemente la distancia ideológica que separa a su partido de este grupo confederado, al que considera su oponente. Seguidamente, examinaremos la fotografía deslegitimadora de Ciudadanos que, recíprocamente, confeccionan, también mediante proyecciones metafóricas, los portavoces del grupo confederado, quienes identifican al partido de Albert Rivera como uno de sus contrincantes.

\subsection{El retrato de Unidos Podemos y sus confluencias según Ciudadanos}

Albert Rivera, portavoz de Ciudadanos, es quien, con sus intervenciones, va tejiendo a través del establecimiento de correspondencias la imagen adversa de los integrantes del grupo parlamentario confederado y, muy especialmente, de quien es su rostro público más conocido, Pablo Iglesias, líder de Podemos.

El diseño de este retrato del adversario se asienta sobre una única línea argumental, que deslegitima a los miembros de este partido por su inacción, por considerar que en lugar de actuar sobre la realidad para transformarla, como correspondería a un político, la observan o la comentan. Al servicio de este rasgo, esencialmente contrario al objetivo del discurso político-la incitación a hacer-, identificamos tres representaciones metafóricas, que proyectan a los integrantes de este grupo parlamentario sobre marcos cognitivos que focalizan pertinazmente la inoperancia, la ineficacia.

La primera de estas representaciones da lugar a la metáfora LOS MIEMBROS DE PODEMOS Y SUS CONFLUENCIAS SON COMENTARISTAS, ${ }^{23}$ a la que acude tenazmente Albert Rivera para denigrar a los adversarios, a los que describe, en diversas instanciaciones, como comentaristas, comentaristas de la realidad, comentaristas del verano, comentaristas de los pactos anticorrupción de los demás o comentaristas del paisaje. Con ella, según hemos señalado, el usuario resalta la ineficacia como atributo definitorio de esta formación y lo contrapone al que, en su opinión, distingue a los miembros de la suya, quienes han venido a la política-dice-a cambiar las cosas sudando, trabajando (1), como una y otra vez reitera en los fragmentos siguientes: ${ }^{24}$

23 A lo largo de este artículo mantenemos la convención tipográfica propia de los estudios basados en la teoría de la metáfora conceptual de representar en versalita tanto las metáforas conceptuales como los dominios cognitivos sobre los que se proyectan las nociones que se representan mediante tales metáforas.

24 Todos los fragmentos extractados del corpus van acompañados de la fecha de la sesión en la que aparecen y de la página en la que figuran, según los datos publicados en la web oficial 
1) Y ese es el acuerdo que tenemos que poner encima de la mesa, el de la vieja política y los viejos partidos con la nueva política, que no ha venido a hacer proclamas, por lo menos Ciudadanos; que no ha venido a hacer épica de laboratorio, por lo menos Ciudadanos; que ha venido a cambiar las cosas sudando, trabajando y no haciendo de comentaristas. Por tanto, hemos venido aquí a trabajar.

(Sesión del 31/08/2016, p. 38)

2) Por eso, señorías, no subo a esta tribuna, como otros, para hacer de comentaristas de la realidad, de comentaristas del verano. Este verano algunos han estado comentando la realidad-a pesar de ser ya diputados y no solo activistas - y otros nos hemos dedicado a trabajar, nos hemos dedicado a intentar desbloquear la situación, nos hemos dedicado a poner encima de la mesa aquello que nos une y no a buscar lo que nos divide.

(Sesión del 31/08/2016, pp. 38-39)

3) En vez de hacer de comentaristas de los pactos anticorrupción de los demás, propongo que lo firmen, que Podemos y el Partido Socialista, que ya lo firmó también con nosotros, lo solemnicemos.

(Sesión del 31/08/2016, p. 43)

4) Brevemente. No le puedo dedicar al señor Iglesias todo el tiempo que él nos ha dedicado a nosotros básicamente porque nosotros tenemos que explicar reformas y usted comentar el paisaje.

(Sesión del 31/08/2016, p. 44)

En la misma línea argumentativa, y con idéntica intención de denigrar la inoperancia del contrario, aparece la metáfora LOS MIEMBROS DE PODEMOS Y SUS CONFLUENCIAS SON GURÚS QUE VENDEN HUMO, que los describe como personas que desarrollan su liderazgo en el terreno de las ideas, como sucede con los líderes espirituales o religiosos, sin que sus actuaciones produzcan efecto alguno a la hora de transformar la realidad del ciudadano

del Congreso de los Diputados de España (<http://www.congreso.es $>$ ). Por otra parte, y con el fin de evitar reiteraciones excesivas en el cuerpo principal del artículo, recogemos en nota a pie otras dos muestras en las que se reitera la misma metáfora conceptual y en las que, por tanto, se identifica a los miembros de los diversos partidos del grupo confederado con comentaristas:

Nosotros no hemos hecho de comentaristas, hemos estado trabajando este verano.

(Sesión del 31/08/2016, p. 42)

En definitiva, una reforma institucional que no hemos visto en los últimos años, que los comentaristas del verano no son capaces de practicar si no trabajan y no negocian.

(Sesión del 31/08/2016, p. 43) 
para mejorarla, que es, en definitiva, la función que se espera de un político. Por otra parte, además, tales gurús se califican de vendehúmos, un compuesto con el que no solo se tilda a esta formación política de ostentosa y presuntuosa, según señala el Diccionario de la lengua española ${ }^{25}$ sino con el que además se acentúa la idea de inoperancia, mediante la presencia del sustantivo humo, que una vez más apunta hacia esa dimensión intangible, inmaterial y etérea en la que, según afirma el usuario, se desenvuelven estos dirigentes:

5) Esa es la diferencia entre los gurús que venden humo y los que somos capaces de proponer políticas sociales que se pueden pagar.

(Sesión del 31/08/2016, p. 40)

El mismo atributo se sustancia, finalmente, en una tercera y última metáfora, LOS MIEMBROS DE PODEMOS Y SUS CONFLUENCIAS SON CASCOS AZULES, que Rivera emplea para identificar al antagonista con las fuerzas de paz de la ONU, comúnmente denominadas cascos azules, a las que se les asigna la función de observar en áreas de conflicto para crear y mantener la paz; con este marco se focaliza nuevamente la inacción, la condición de observadores, cuya gestión no trasciende en obras concretas:

6) Así que ojalá Podemos deje de esquivar el pacto antiterrorista nacional y se sume, no venga de observador-no son cascos azules, son ustedes diputados-, vengan ustedes a participar de la lucha contra el terrorismo y no a verla de lejos.

(Sesión del 31/08/2016, p. 51)

\subsection{El retrato de Ciudadanos según Unidos Podemos y sus confluencias}

Seguidamente, nos ocupamos de la representación deslegitimadora de Ciudadanos que confeccionan, recíprocamente, los portavoces del grupo parlamentario confederado integrado por Unidos Podemos, En Comú Podem y En Marea, quienes trazan este retrato sobre la base de cuatro pilares conceptuales (cada uno de los cuales se materializa en metáforas diversas): Ciudadanos es una réplica del PP; Ciudadanos es un partido sin ideología; Ciudadanos es un partido efímero; $y$, finalmente, Ciudadanos es un partido neoliberal.

El primero de estos pilares, Ciudadanos es una réplica del PP, se concreta en tres metáforas conceptuales acuñadas por el portavoz de Podemos, Pablo Iglesias, que proyectan la fuerza política sobre tres marcos cognitivos que comparten la idea de dependencia, sumisión, apoyo, y que representan a

25 Real Academia Española \& Asociación de Academias de la Lengua Española, Diccionario de la lengua española; disponible en <http://dle.rae.es/?w=diccionario> (consultado el 3 de febrero de 2019). 
Ciudadanos como un partido sometido y rendido al PP: FILIAL, HIPOTECA y, por último, MULETA.

El marco FILIAL nos proporciona una metáfora (CIUDADANOS ES LA FILIAL DEL $P P$ ), instanciada en dos ocasiones, que convierte a este partido, según indica el Diccionario de la lengua española ${ }^{26}$ en una entidad subordinada y dependiente de otra principal, que se identifica aquí con el PP:

7) Ustedes y su filial naranja pretenden seguir aplicando una política económica cuya prioridad absoluta es reducir el déficit público.

(Sesión del 31/08/2016, p. 23)

8) El acuerdo que nos ha presentado [...] representa la voluntad de continuar con su equipo filial por la senda de la ineficacia económica, la injusticia social y la corrupción.

(Sesión del 31/08/2016, p. 24)

En el primero de estos extractos (7), el partido de Albert Rivera se conceptúa como la filial naranja del $\mathrm{PP}$, definiendo así a esta agrupación política, reproducida aquí a través del color naranja predominante en su logo, como una fuerza secundaria, sometida a la principal, que es el PP. En el segundo fragmento extractado (8), la metáfora se inserta en el dominio cognitivo del deporte, tantas veces empleado en el discurso político, e identifica a esta formación con el equipo filial del PP, con un equipo menor, conformado por jugadores provenientes de las categorías base de un equipo profesional, que una vez más se corresponde con el PP. ${ }^{27}$

Pablo Iglesias insiste en esta misma línea de focalizar el sometimiento del partido Ciudadanos al ideario del PP mediante una segunda metáfora conceptual que lo correlaciona con el dominio origen HIPOTECA (CIUDADANOS ES LA HIPOTECA NARANJA) y que lo deslegitima por entender que esta organización ha contraído obligaciones con el PP de cuyo cumplimiento debe responder y que, por consiguiente, está hipotecada. ${ }^{28}$ Con la adición del adjetivo naranja al sustantivo hipoteca, en alusión, como hemos señalado, al color predominante en el símbolo gráfico de este partido, el portavoz de Podemos incorpora un doble juego, pues al tiempo que reproduce objetivamente su

26 Real Academia Española \& Asociación de Academias de la Lengua Española, Diccionario de la lengua española, $<\mathrm{http} / / /$ dle.rae.es/?w=diccionario $>$.

27 A propósito de la recurrencia del discurso político al marco cognitivo del deporte como cantera para la construcción de metáforas conceptuales, puede consultarse Marina Díaz Peralta \& Gracia Piñero Piñero, 'El dominio conceptual del deporte para la construcción de metáforas deslegitimadoras en el discurso de la extrema derecha española', Estudios Filológicos, 63:1 (2018), 229-46.

28 Así es como la Real Academia Española y la Asociación de Academias de la Lengua Española definen el término hipotecar en su Diccionario de la lengua española (<http://dle. rae.es/?w=diccionario $>$ ). 
imagen corporativa, activa en la mente del receptor una campaña publicitaria desarrollada entonces por un conocido banco en línea, que promocionaba en estos mismos términos una hipoteca sin comisiones. Con este sintagma, y con los calificativos que seguidamente añade, Iglesias desacredita a Ciudadanos tildándola de fuerza poco fiable y desleal, al recordar a la audiencia que su líder es capaz de pactar con grupos muy heterogéneos, como demuestra el hecho de que en la anterior legislatura lo hiciera con el PSOE y de que en la actual se presente pactando con un partido de ideología contraria como el PP:

9) No sé si recuerda usted que desde esta tribuna le advertí de los peligros de la hipoteca naranja. Supongo que estará usted de acuerdo conmigo en que no han sido los socios más fiables ni más leales a la vista de lo que estamos viendo hoy.

(Sesión del 31/08/2016, p. 25)

Por último, la categorización de Ciudadanos como réplica ideológica del PP se reitera mediante su correspondencia con el dominio fuente MULETA (CIUDADANOS ES LA MULETA DEL PP), que convierte a este partido en apoyo, en una entidad que ayuda a mantener a otra—según la información que nos proporciona el citado Diccionario de la lengua española -, proyectada aquí sobre la vieja política, en referencia al bipartidismo del PSOE y del PP que durante los últimos años ha predominado en España:

10) Ustedes nacieron para frenar el cambio y para ser la muleta de lo viejo. (Sesión del 31/08/2016, p. 24)

La segunda línea argumental sobre la que descansa el retrato efectuado por los confederados desacredita a Ciudadanos como un partido sin ideario o de perfiles ideológicos imprecisos, que se conceptualiza, en el discurso de Pablo Iglesias, a través de dos metáforas deslegitimadoras de carácter intertextual, ${ }^{29}$ originadas, como hemos indicado, en la experiencia cultural del hablante. Con ellas Iglesias desaprueba la habilidad de Ciudadanos para negociar con agrupaciones de distinto signo, con el argumento ya señalado de acudir al debate de investidura anterior con un acuerdo con el PSOE y de presentarse al actual aliado con el PP.

La primera de ellas (CIUDADANOS ES LA MARIONETA GATOPARDIANA DE LAS ÉLITES) deslegitima al líder de este partido, quien, representado como marioneta gatopardiana, resulta doblemente descalificado: en primer lugar, por su condición de marioneta, que lo define como un individuo manejado

29 Información sobre estas metáforas intertextuales puede obtenerse en estas obras ya citadas: Zinken, 'Ideological Imagination: Intertextual and Correlational Metaphors in Political Discourse'; y Zinken, Hellsten \& Nerlich, 'What Is "Cultural" about Conceptual Metaphors?'. 
por otro, carente de criterio propio; y en segundo lugar, por su gatopardismo, que identifica a Rivera con Tancredi, el personaje de la novela de Lampedusa, El gatopardo, cuya conocida sentencia ('Si queremos que todo siga como está, necesitamos que todo cambie') ha dado lugar en ciencias políticas al denominado gatopardismo o propósito de cambiar todo para que nada cambie:

11) [...] usted no es ni de izquierdas ni de derechas; usted es de lo que haga falta y de lo que le ordenen desde arriba, porque usted no manda ni siquiera en su partido. Le iba a decir a usted que es la marioneta gatopardiana de las élites [...].

(Sesión del 31/08/2016, p. 24)

Sin embargo, Iglesias presupone que Rivera carece de las claves culturales necesarias para acceder a la interpretación de esta primera correspondencia y por ello cree necesario insistir en esta línea argumental, la ausencia de ideario, reformulándola a través de una segunda metáfora intertextual (CIUDADANOS ES EL CHICLE DE MACGYVER), con la que el líder de Ciudadanos, antes marioneta gatopardiana, se transforma ahora en el chicle de MacGyver del régimen, en clara alusión a esa versatilidad que lo hace capaz de lograr pactos con fuerzas políticas dispares, como son la del PP y la del PSOE. Esta nueva referencia cultural, más simple y de fácil acceso, es, en opinión de Iglesias, mucho más ajustada al perfil de su destinatario:

12) Le iba a decir a usted que es la marioneta gatopardiana de las élites, pero creo que me entenderá mejor si le digo que es usted el chicle de MacGyver del régimen: vale usted para todo [...]. Es lo que tiene ser el chicle de MacGyver: dura lo que dura.

(Sesión del 31/08/2016, p. 24)

Mediante esta proyección, el portavoz de Podemos, de manera satírica y mordaz, descalifica a su interlocutor, a quien, además de atribuirle su incompetencia para interpretar la metáfora anterior, le imputa la carencia de un ideario sólido, que se manifiesta en una ilimitada capacidad de diálogo, tan flexible y elástica como la del chicle de MacGyver, el agente secreto que protagoniza la serie de televisión estadounidense creada en 1985 por Lee David Zlotoff, quien improvisa soluciones eficaces en momentos de gran tensión con artilugios variopintos y muy especialmente con la goma de mascar.

Una tercera línea de conceptualización desacreditadora, según los portavoces del grupo confederado, define a Ciudadanos como un partido efímero, que no está llamado a permanecer en el escenario político español. Este eje se concreta en la metáfora que aporta Pablo Iglesias, perfilada sobre el dominio BURBUJA (CIUDADANOS ES UNA BURBUJA), con la que describe y valora a esta formación como un partido fugaz, que, cual pompa de jabón, estallará y se diluirá en un corto espacio de tiempo: 
13) [...] pero me temo que la burbuja naranja se está desinflando y este intento de investidura fallida va a dejarles a ustedes ocupando el papel que les corresponde. Es lo que tiene ser el chicle de MacGyver: dura lo que dura.

(Sesión del 31/08/2016, p. 24)

Finalmente, la fotografía adversa de Ciudadanos efectuada por los diversos portavoces del grupo Unidos Podemos y sus confluencias mediante proyecciones se completa con una última línea argumental, que ancla la ideología de esta formación a las doctrinas del neoliberalismo. En esta ocasión es Alexandra Fernández, la portavoz de la agrupación gallega En Marea, quien, partiendo una vez más de la conceptualización de Ciudadanos como la nueva derecha, como una réplica ideológica de la vieja derecha, acude a la metáfora intertextual LOS MIEMBROS DE CIUDADANOS SON LA REENCARNACIÓN DE LOS CHICAGO BOYS, para identificar a sus militantes con aquel grupo de economistas chilenos formados durante los años 60 en la Universidad de Chicago, quienes, al regresar a su país, tuvieron una influencia decisiva en el régimen de Augusto Pinochet:

14) [...] este pacto entre la vieja derecha y la nueva derecha, entre la tradición de los que nacieron para mandar el cortijo a golpe de sobre y esta reencarnación posmoderna de los Chicago boys tiene como objetivo coger de nuevo el timón de la nave para pisar el acelerador de los recortes y de las privatizaciones.

(Sesión del 31/08/2016, p. 28)

\section{Conclusiones}

El trabajo desarrollado en estas páginas ha puesto de manifiesto la eficacia de un marco teórico tripartito, constituido por el análisis crítico del discurso, la teoría de la metáfora conceptual y, por último, el concepto de metadiscurso, para el estudio de la comunicación política. En nuestra opinión, se trata de un enfoque especialmente adecuado para abordar los textos que encaja en una concepción integradora de la comunicación política, en la que se incluye tanto la producción discursiva de los representantes públicos en el ejercicio de sus funciones, como los textos producidos por los ciudadanos cuando intervienen en el espacio público para opinar sobre los temas de interés colectivo o para interpelar a actores e instituciones del Estado con la pretensión de influir en sus decisiones. ${ }^{30}$ Todas estas muestras textuales

30 Patrick Charaudeau, 'La argumentación persuasiva: el ejemplo del discurso político', en Haciendo discurso. Homenaje a Adriana Bolívar, ed. Martha Shiro, Paola Bentivoglio \& Frances de Erlich (Caracas: Univ. Central de Venezuela, 2009), 277-95; Nicolás Bermúdez, 'Tipología y discurso político', Signo y Seña, 22 (2012), 139-63; Cristián González Arias \& Juan Satt Román, 'Modalidad deóntica como expresión de la regulación social en el discurso 
constituyen un material especialmente idóneo para examinar estrategias discursivas que ponen al descubierto que el texto, escenario de la interacción social, constituye un espacio en el que convergen las dimensiones cognitiva, social e ideológica de la comunicación.

En este caso, hemos aplicado tales planteamientos al estudio del discurso parlamentario español, con el fin de estudiar las metáforas conceptuales con las que los portavoces de los nuevos partidos políticos que debutaron en el parlamento español en la XI legislatura, y cuya presencia se confirmó en la siguiente, diseñan el retrato ideológico del adversario.

Con estos presupuestos, hemos constatado que la metáfora conceptual constituye una herramienta cognitiva que no solo contribuye a la simplificación del contenido ideacional del texto $y$, por tanto, guía al receptor en su proceso de interpretación; sino que, además, coopera en el establecimiento de la posición del hablante y del modo en que este se relaciona con sus interlocutores y con sus respectivos criterios. Por consiguiente, y a pesar de que nunca ha sido explícitamente inventariada como tal, parece lógico reclutar la metáfora como mecanismo del metadiscurso característico de la comunicación política, tanto en su dimensión interactiva como en su dimensión interaccional. ${ }^{31}$

Hemos constatado que en la metáfora, fórmula que va más allá de lo exclusivamente lingüístico para adentrarse en mecanismos de representación categorial encaminados a la transmisión eficaz del pensamiento, de las creencias y de la ideología, confluyen los tres procedimientos en los que, según Patrick Charaudeau, ${ }^{32}$ se materializa la estrategia de simplificación característica del discurso político: esto es, la singularización, que evita la multiplicación de las ideas; la esencialización, que logra la contención de las ideas; y, por último, la analogía o establecimiento de comparaciones. Se trata de una estrategia que, como señala Gladys Lucía Acosta, se orienta a la búsqueda del 'mayor consenso posible en el marco de las ideas y creencias que porta el grupo al que se dirige'. ${ }^{33}$

Hemos advertido también que, a través de la metáfora, que, de acuerdo con lo señalado, combina la ruta central de la persuasión con la periférica, se activan estrategias argumentativas y, muy especialmente, estrategias para entrar en contacto con los afectos de la audiencia, pues las emociones son 'el garante de la cohesión social, permiten al individuo constituir su

político ciudadano en las cadenas de comentarios en blogs de periodismo', Ibérica, 32 (2016), 201-20.

31 Véase Hyland, Metadiscourse, 30.

32 Charaudeau, 'La argumentación persuasiva', 285.

33 Gladys Lucía Acosta V., 'Deslegitimación en el discurso político: un análisis de las declaraciones oficiales y de sus réplicas frente al movimiento social y político Marcha Patriótica', Discurso \& Sociedad, 7:2 (2013), 364-91 (p. 371). 
sentimiento de pertenencia a un grupo, representan la vitalidad de la conciencia colectiva'. ${ }^{34}$

Hemos observado que en el género del debate parlamentario las metáforas constituyen una estrategia esencial en la gestión del conocimiento en el discurso público y, consecuentemente, su elección es 'crucial para nuestra comprensión de los hechos sociales y políticos'. ${ }^{35}$

En este contexto, las correspondencias metafóricas que diseñan el retrato ideológico del adversario contribuyen a la función estratégica de deslegitimación característica del discurso político y particularmente del debate parlamentario, ${ }^{36}$ donde adquieren, como suele suceder con los mecanismos metadiscursivos, un comportamiento determinado, pues 'topic, register, genre and discourse impose their own metaphorical reasoning' . ${ }^{37}$

Nuestro análisis nos ha permitido constatar de igual modo que en el discurso parlamentario, y en el contexto de una planificada política de imagen, se combinan las metáforas correlacionales, fundamentadas en la experiencia corpórea, junto con las metáforas intertextuales, fundamentadas en la experiencia cultural, para dibujar la ideología del antagonista político.

En nuestro caso, hemos observado que el retrato negativo del grupo parlamentario Unidos Podemos y sus confluencias, según lo diseña Ciudadanos, se asienta sobre una única línea argumental, que deslegitima a los miembros de estos partidos por su inacción. Al servicio de este rasgo, identificamos tres representaciones metafóricas, que focalizan insistentemente la ineficacia de estas fuerzas: LOS MIEMBROS DE PODEMOS Y SUS CONFLUENCIAS SON COMENTARISTAS, LOS MIEMBROS DE PODEMOS Y SUS CONFLUENCIAS SON GURÚS QUE VENDEN HUMO y, por último, LOS MIEMBROS DE PODEMOS Y SUS CONFLUENCIAS SON CASCOS AZULES.

Los portavoces del grupo parlamentario confederado integrado por Unidos Podemos, En Comú Podem y En Marea trazan, recíprocamente, una representación deslegitimadora de Ciudadanos sobre la base de cuatro líneas definitorias, cada uno de las cuales se materializa en metáforas diversas.

La primera de estas líneas, Ciudadanos es una réplica ideológica del PP, se concreta en tres metáforas conceptuales que proyectan la fuerza política sobre

34 Patrick Charaudeau, 'Las emociones como efectos de discurso', Versión, 26 (2011), 97118 (p. 99).

35 Van Dijk, 'Discurso, conocimiento, poder y política', 182-83.

36 Paul Chilton \& Christina Schäffner, 'Introduction: Themes and Principles in the Analysis of Political Discourse', en Politics As Talk and Text: Analytic Approaches to Political Discourse, ed. Paul Chilton \& Christina Schäffner (Amsterdam/Philadelphia: John Benjamins, 2002), 1-41.

37 Inesa Šeškauskienè, 'Metaphoricity of Academic Metadiscourse: What Can Be Raised in English and Lithuanian?', en Anglistics in Lithuania: Cross-Linguistic and Cross-Cultural Aspects of Study, ed. Inesa Šeškauskienè \& Jonè Grigaliūnienė (Newcastle upon Tyne: Cambridge: Scholars Publishing, 2013), 93-120 (p. 98). 
marcos cognitivos que comparten la idea de subordinación, apoyo, y que representan a Ciudadanos como un partido sometido al PP a través de las correspondencias siguientes: CIUDADANOS ES LA FILIAL DEL PP, CIUDADANOS ES LA HIPOTECA NARANJA DEL $P P$, y, por último, CIUDADANOS ES LA MULETA DEL $P P$.

La segunda línea argumental sobre la que descansa el retrato efectuado por los confederados, Ciudadanos es un partido de perfiles ideológicos imprecisos, se conceptualiza a través de dos metáforas intertextuales que desaprueban la habilidad de esta formación para negociar con agrupaciones de distinto signo ideológico: CIUDADANOS ES LA MARIONETA GATOPARDIANA DE LAS ÉLITES y CIUDADANOS ES EL CHICLE DE MACGYVER DEL RÉGIMEN.

Una tercera línea de conceptualización desacreditadora según los portavoces del grupo confederado define a Ciudadanos como un partido efímero, a través de la metáfora que se perfila sobre el dominio BURBUJA (CIUDADANOS ES UNA BURBUJA), que describe y valora a esta formación como un partido fugaz.

Finalmente, la fotografía adversa de Ciudadanos efectuada por los diversos portavoces del grupo Unidos Podemos y sus confluencias se completa con un último eje argumental, que ancla la ideología de esta formación a las doctrinas del neoliberalismo, mediante la proyección LOS MIEMBROS DE CIUDADANOS SON LA REENCARNACIÓN DE LOS CHICAGO BOYS.

En definitiva, a través de la metáfora, y mediante la selección de los marcos cognitivos sobre los que proyecta las categorías que pretende aclarar y explicar, el político combina argumentación y emoción, logos y pathos, en el ejercicio de ese soft power, de ese poder simbólico del que nos habla Joseph Nye, ${ }^{38}$ centrado en el lenguaje de la narración del mundo en forma de historias coherentes y persuasivas, para lograr que la audiencia desee lo que él mismo desea.*

38 Joseph S. Nye, Soft Power: The Means to Success in World Politics (New York: Public Affairs, 2004), 5.

* Cláusula de divulgación: la autora ha declarado que no existe ningún posible conflicto de intereses. 